\title{
Causes of Deficits in Waste Management Systems in Saharanpur City
}

Arvind Kumar Arora

School of Agriculture \& Environmental

Sciences, Shobhit University, Gangoh,
Dr. N.C. Mishra

Asso. Prof., Dept. of Polymer and

Process Engineering, IIT Roorkee

Saharanpur

\section{Dr. Mohd. Vasseem}

Asstt. Prof., School of Agriculture \& Environmental Sciences, Shobhit University, Gangoh, Saharanpur

Abstract

Saharanpur city is a prominent city in northern Uttar

Pradesh. Not only is the city densely populated, it also has several industries. This leads to generation of large quantities of wastes. However, the existing waste management system in the city is not well executed. The proof of this can be seen in the form of large piles of waste in several parts of the city. This paper lists the deficits of the waste management system in Saharanpur city and the underlying causes of these issues.

Keywords: waste management systems

\author{
Reference to this paper \\ should be made as \\ follows: \\ Arvind Kumar Arora, \\ Dr. N.C. Mishra, \\ Dr. Mohd. Vasseem \\ Causes of Deficits in \\ Waste Management \\ Systems in Saharanpur \\ City, \\ Journal Global Values \\ Vol. XI, No.I \\ Article No.09 \\ pp.67-72 \\ http://anubooks.com/ \\ ?page_id $=6195$ \\ https://doi.org/ \\ $10.31995 /$ \\ jgv.2020.v11i01.009
}


Causes of Deficits in Waste Management Systems in Saharanpur City

Arvind Kumar Arora, Dr. N.C. Mishra, Dr. Mohd. Vasseem

\section{Introduction}

Solid waste refers to the range of garbage arising from animal and human activities that are discarded as unwanted and useless. Solid waste is generated from industrial, residential and commercial activities in each area, and may be handled in a variety of ways. As such, landfills are typically classified as sanitary, municipal, construction and demolition or industrial waste sites.

Waste can be categorized based on material, such as plastic, paper, glass, metal, and organic waste. Categorization may also be based on hazard potential, including radioactive, flammable, infectious, toxic, or non-toxic. Categories may also pertain to the origin of waste, such as industrial, domestic, commercial, institutional or construction and demolition.

Regardless of the origin, content or hazard potential, solid waste must be managed systematically to ensure environmental best practices. As solid waste management is a critical aspect of environmental hygiene, it needs to be incorporated into environmental planning.

Solid Waste Management is defined as the discipline associated with control of generation, storage, collection, transport or transfer, processing and disposal of solid waste materials in a way that best addresses the range of public health, conservation, economics, aesthetic, engineering and other environmental considerations.

In its scope, solid waste management includes planning, administrative, financial, engineering and legal functions. Solutions might include complex interdisciplinary relations among fields such as public health, city and regional planning, political science, geography, sociology, economics, communication and conservation, demography, engineering and material sciences. The functional elements of waste management are listed below.

1. Waste generation refers to activities involved in identifying materials which are no longer usable and are either gathered for systematic disposal or thrown away.

2. Onsite handling, storage, and processing are the activities at the point of waste generation which facilitate easier collection. For example, waste bins are placed at the sites which generate enough waste.

3. Waste collection, a crucial phase of waste management, includes activities such as placing waste collection bins, collecting waste from those bins and accumulating trash in the location where the collection vehicles are emptied. 
Although the collection phase involves transportation, this is typically not the main stage of waste transportation.

4. Waste transfer and transport are the activities involved in moving waste from the local waste collection locations to the regional waste disposal site in large waste transport vehicles.

5. Waste processing and recovery refer to the facilities, equipment, and techniques employed both to recover reusable or recyclable materials from the waste stream and to improve the effectiveness of other functional elements of waste management.

6. Disposal is the final stage of waste management. It involves the activities aimed at the systematic disposal of waste materials in locations such as landfills or waste-to-energy facilities.

As explained above, waste management is a multifaceted problem and requires systematic planning for proper implementation. Therefore, it is highly important to understand the current management methods and identify the aspects that require improvement. This paper aims at presenting the problems and their causes in the waste management system in Saharanpur city.

\section{Principal Deficits in the system}

At present the entire system in practice in the greater part of the city is unscientific and unhygienic causing serious problem of health and environmental degradation through air, land and water contamination. This makes it highly important to study the problem at hand and propose a feasible solution. The issues that are applicable to the existing solid waste management system [1] are listed below.

1. Absence of any systematic waste collection and segregation process with complete coverage.

2. Absence of any waste processing and treatment facility.

3. Open disposal of waste near to the roads and in open drains.

4. Generation of bulk quantity of waste during festive seasons.

5. Uncontrolled disposal of waste at the source of generation.

6. Absence of sufficient manpower and suitable infrastructural facilities for wastemanagement.

7. No waste management practices.

8. Lack of awareness among people towards waste management.

9. Negligible storage of waste at source.

10. Minimal segregation of recyclables. 
Causes of Deficits in Waste Management Systems in Saharanpur City

Arvind Kumar Arora, Dr. N.C. Mishra, Dr. Mohd. Vasseem

11. Partial primary collection from doorstep.

12. Irregular street sweeping.

13. Open and unhygienic water storage depots.

14. Manual transportation of waste (in open tractors and / or truck).

15. Minimal processing of municipal solid waste.

16. Unscientific disposal of waste at a dumping ground where waste is allowed to decay and burn.

17. The waste is neither spread nor covered.

\section{Causes of the deficits}

In our country some of the key reasons attributed to inefficient SWM services in a small town (e.g. Saharanpur) are a result of lack of community participation, apathy of the political leadership and municipal officer, low productivity of labour, strong labour union having political patronage, indiscipline among the work force, inept handling of labour issue, virtual lack of supervision and control, and lack of human and financial resources. Saharanpur Nagar Nigam (SNN) [2] is not able to raise adequate financial resources through taxation or levy of user fees. The recovery mechanism is inefficient and large number of properties within a municipal boundary are presently not accounted for in the record book, the financial recourses are, therefore, limited and often not utilize judiciously for the improvement of essential SWM services. It is evident from a recent survey that only $18 \%$ of the latrines are connected to sewer and 53 percent to septic tank. In all the socio-economic groups existence of dry pit latrine was found and the overall percentage was as high as almost 20. Some were found to polluting water bodies in LIG and slum location. There are a few public/community toilets in the city as reported by $4 \mathrm{HHs}$. But only 40 percent were satisfied with the facilities.

About $70 \%$ of the city is covered by sewerage system. There are two storm water drains i.e. Paon Dhoi and Damohla flowing through the city. Kregi Nala is also flowing in between the city. Localities lacking proper drainage facilities. Many drains are chocked with garbage due to which some of the areas have water logging problems. To minimize the pollution of Paon Dhoi Nadi, a sewer line has been laid and the drains have been diverged in the sewer lines to keep clean the environment of this river under Yamuna Action Plan. Some more part of the eastern areas of the city beyond Dhamola River and Mandi Samittee Areas, Chilkana Road, Beri Bagh etc are also under cover of YAP.

The City is confronted with several problems as the development is taking place along major roads. The unauthorized constructions are also taking place in the 
form of lintels on drains as well as illegal projection over the streets. Saharanpur Development Authority is unable to remove the same and the powers of the Municipality have been ceased which is alternatively a great financial loss to the Municipality.

In the absence of Master Plan of Drainage of the city, the open drains remain choked throughout the year and specially in the rainy season which ultimately results water logging in several parts of the City creating health hazards. The basic reason is also shortage of manual, sweeping staff. Storm drains are being desalted by Nala Cleaning JCB machines based on the decollating Programme. It is remarkable here that Paon Dhoi is also another big source of disposal of water and there is great need to desalt the river in the improvement interest of the environment.

At present city having sewer system in its $2 / 3$ part and rest of $1 / 3$ part that is nearby area of Paondhoi and Dhamola River side slum areas has no sever system. Total slope of the city lying towards to the Paon Dhoi River and Dhamola River. The main nala of the Saharanpur city is Caraegi Nala and flowing almost middle of the city. There are another so many nala's are situated in the various parts of the city. All these nalas are broken from the various portions and chocked due to the improper management. Due to this reason, disposal of drainage and waste water interrupted and in rainy season all nalas are overflow. A sewage plant situated in the Southern part of the city near Dhamola River.

The drainage system of Saharanpur city is creating serious problems of water logging specially during rainy season in low land areas. Nalas are without side walls resulting situation due to erosion size. The two river Paon Dhoi Nadi and Dhamola Nadi passes through heart of the City. There are four main nalas in the city which carriage the surface water which is ultimately flows in the above two river's:

1. The total length of the craigi nala is $3.25 \mathrm{~km}$. which starts from Partap Nagar and passes through Goteshah, Idgah, Joghyan, Kishanpura and at last dropped in Dhamola river most of the portion of the side walls of the nala do not exist.

2. Chilkana Road Nala starts fromRajwaha and passes through Samrat Vikram Colony, Madan Puri, Khata Khari and Mata Ghar and ultimately dropped in the river Paon Dhoi Nadi. The excreta bed of the Nala is not sufficient to carry out the entire discharge.

3. Sharda Nagar Nala which starts from LabourColony Rajwaha and passes through Sharda Nagar Ambala Road and meets into Craegi Nala . The nala 
Causes of Deficits in Waste Management Systems in Saharanpur City

Arvind Kumar Arora, Dr. N.C. Mishra, Dr. Mohd. Vasseem

is pucca but due to silting, it comes over flow and could not carry out the full volume of water. The total length of the Nala is about $12.17 \mathrm{~km}$.

4. Chakrata road nala which starts from Numaish Camp Road crossing and passes through Hiran Maran, Meerkot, Zafarnawaj and finally meets into the Paon Dhoi Nadi. Most part of the Nala is under ground and it is about $0.75 \mathrm{~km}$.

Besides of the above, main nala there are large number of connecting drains some drains are passing through Railway areas.

As discussed above, the system in place have several issues and is in dire needs of better planning and implementation. Another aspect besides this the lack of awareness. Saharanpur is a densely populated city and thus requires a well-executed awareness program. Attention should be paid while informing people by making the information easy to understand and attractive to implement.

\section{Conclusion}

As presented in this paper, the amount of waste generated in Saharanpur city is high while the current system for management of this waste is lacking in several ways. There is a high deficit of manpower, awareness among common populace and waste management facilities. The reasons for these problems were also presented in the sections above. While knowing that the system has deficits is essential, it is also important to use this knowledge for future improvements. By presenting the causes of these deficiencies in a structured manner it is intended foraiding SWM system planners to help improve the conditions in the city.

\section{References}

1 Saharanpur Nagar Nigam Survey, Saharanpur development Authority Master plan.

2 SNN ULB SBMSurvey.

3 Central Public Health \& Environmental Engineering Organisation (CPHEEO), Ministry of Housing and Urban Affairs, Government of India, Pages 140-180. 